\title{
ABC Based Design of PID Controller for Two Area Load Frequency Control with Nonlinearities
}

\author{
M. Elsisi ${ }^{11}$, M. Soliman ${ }^{2}$, M. A. S. Aboelela ${ }^{3}$, W. Mansour ${ }^{4}$ \\ ${ }^{1,2,4}$ Electrical Power and Machines Department, Faculty of Engineering (Shoubra), Benha University, \\ Cairo, EGYPT. 108 Shoubra St., B.O. Box 11241, Tel.: +20 01011793910 \\ ${ }^{3}$ Electrical Power and Machines Department, Faculty of Engineering, Cairo University, Giza, Egypt. \\ *Corresponding author, e-mail: elsisimahmoud22@yahoo.com
}

\begin{abstract}
This paper presents an application of the Artificial Bee Colony $(A B C)$ to optimize the parameters of Proportional-Integral-Derivative controller (PID) of nonlinear Load Frequency Controller (LFC) for a power system. A two area non reheat thermal system is equipped with PID controller. ABC is employed to search for optimal controller parameters to minimize the time domain objective function. The performance of the proposed technique has been evaluated with the performance of the conventional Ziegler Nichols (ZN), Genetic Algorithm (GA) and Bacterial Foraging Optimization Algorithm (BFOA) in order to demonstrate the superior efficiency of the proposed $A B C$ in tuning $P I D$ controller. By comparison with the conventional technique, GA and BFOA, the effectiveness of the proposed $A B C$ is validated over different operating conditions, and system parameters variations.
\end{abstract}

Keywords: LFC, PID, power system control, artificial bee colony

Copyright $@ 2015$ Institute of Advanced Engineering and Science. All rights reserved.

\section{Introduction}

Frequency control, during the load and generation imbalance, represents a very imperative issue for large-scale power systems. Automatic generation control (AGC) plays a significant role in the power system by maintaining the scheduled system frequency and tie-line power flow during normal operating conditions and during small perturbations [1-3]. This function of an AGC is always referred to as "load frequency control (LFC)" as mentioned by Kundur [2]. LFC is often considered as one of the first and foremost large-scale, decentralized, robust controllers in engineering practice. LFC is accomplished by two different control actions of the primary speed control and supplementary speed control in an interconnected power system. Several approaches such as optimal, genetic algorithm (GAs), particle swarm optimization (PSO), imperialist competitive algorithm (ICA), bacterial foraging optimization (BFO), etc., for the design and optimization of the LFC system, have been reported in the literature [4-15]. Modern optimal control concept for AGC designs of interconnected power system was firstly presented by Elgerd and Fosha [4-5]. Genetic algorithms (GAs) have been extensively considered for the design of AGC. Optimal integral gains and optimal PID control parameters have been computed by GAs technique for an interconnected, equal non-reheat and reheat type two generating areas [6-7]. Parameter optimization of PID sliding-mode load frequency control used in automatic generating control (AGC) of multi-area power systems with nonlinear elements has been proposed in [8]. In [9], GA is used to compute the decentralized control parameters to achieve an optimum operating point for a realistic system comprising generation rate constraint (GRC), dead band, and time delays. The use of particle swarm optimization (PSO) for optimizing the parameters of AGC, where an integral controller and a proportional-plus-integral controller, is reported in [10]. In 2010, Gozde et al. designed the PSO based PI-controller with the new cost function and compared their results with the results of Abdel-Magid and Abido's study [11]. In [12], A new PID controller for resistant differential control against load disturbance is introduced that can be used for load frequency control (LFC) application. Parameters of the controller have been specified by using imperialist competitive algorithm (ICA). The authors of [13-14] have proposed bacterial foraging optimization algorithm (BFOA) for designing PI and PID-based load frequency controller for two-area power system 
with and without GRC. Application of Gravitational Search Algorithm (GSA) to optimize several important parameters in AGC of an interconnected power systems, has been reported in [15].

Recently $A B C$ has emerged as powerful optimization technique because colonies of bees have instinct ability known as swarm intelligence [16]. These colonies have a high degree of organization to solve problem beyond capability of individual members by functioning collectively and interacting primitively amongst members of the group [17-18]. This paper proposes a new optimization algorithm known as ABC for optimal designing of PID controller for nonlinear LFC to damp power system oscillations. The design problem of the proposed controller is formulated as an optimization problem and $A B C$ is employed to search for optimal controller parameters by minimizing a candidate time-domain based objective function. Simulations results confirm the effectiveness of the proposed controller in providing good damping characteristic to system oscillations over a wide range of loading conditions and system parameters variations. Also, these results validate the superiority of the proposed method in tuning controller compared with BFOA, GA and conventional method.

\section{Artificial Bee Colony Optimization: an Overview}

Recently, Karaboga has proposed $A B C$ algorithm [16]. In a real bee colony, there are special tasks performed by some individuals. These specialized bees maximize the nectar amount stored in the hive by performing efficient division of labour and self-organization. The minimal model of swarm-intelligent forage selection in a honeybee colony which ABC algorithm depend on it, consists of three kinds of bees: employed bees, onlooker bees, and scout bees. Half of the colony consists of employed bees and the other half includes the onlooker bees. Employed bees are exploiting the nectar sources and giving information to the other waiting bees (onlooker bees) in the hive about the quality of the food source site which they are exploiting. Onlooker bees wait in the hive and choose a food source to exploit depending on the information shared by the employed bees. Scouts randomly search the environment in order to find a new food source depending on an internal motivation or possible external guide or randomly.

\subsection{Artificial Bee Colony Algorithm}

The Main steps of the ABC algorithm are given below [17]:

1) Scouts go to the initial food sources.

2) Each employed bee finds a new food source and exploits in the better source.

3) Each onlooker bee chooses a source depending on the quality of her solution produces a new food source in selected food source site and exploits the better source.

4) Decide the source to be abandoned and allocate its employed bee as scout for searching new food sources.

5) Keep the best food source found so far.

6) Repeat Steps 2-5 until the stopping criterion is achieved.

In the first step of the algorithm, solutions are randomly determined in range of parameters. In second step of the algorithm, for each employed bee, a new source is produced by:

$$
V_{i j}=X_{i j}+\phi_{i j}\left(X_{i j}-X_{k j}\right)
$$

Where, $\phi i j$ is a uniformly distributed real random number within the range, $k$ is the index of the solution chosen randomly from the colony.

After producing $V_{i}$, this new solution is compared to $X_{i}$ solution and the employed bee exploits the better source. In the third step of the algorithm, an onlooker bee chooses a food source with the probability

$$
P_{i}=f i t_{i} / \sum_{j=1}^{S N} f i t_{j}
$$

Where, fit $t_{i}$ is the fitness of the solution $X_{i}$ and $S N$ is the number of the food sources. 
After all onlookers are allocated to the sources, sources are checked whether they are to be abandoned. If the source cannot be improved and the number of cycles is greater than a predetermined limit, the source is considered to be exhausted. The employed bee associated with the exhausted source becomes a scout and makes a random search in problem domain by

$$
X_{i j}=X_{j}^{\min }+\operatorname{rand} *\left(X_{j}^{\max }-X_{j}^{\min }\right)
$$

\section{Two Area Power System}

A model of controlled non-reheat thermal plants in two-area interconnected power system is shown in Figure 1 where $f_{i}$ is the system frequency $(\mathrm{Hz}), R_{i}$ is the regulation constant (Hz/unit), $T_{G i}$ is the speed governor time constant (s), $T_{T i}$ is the turbine time constant (s) and $T_{P i}$ is the power system time constant (s), $A C E_{i}$ is the area control error, $\triangle P_{D i}$ is the load demand change, $\Delta P_{c i}$ is the change in speed changer position, $\Delta P_{G i}$ is the change in governor valve position, $K_{P i}$ is the power system gain, and $\Delta P_{t i e}$ is the change in tie line power. In addition, a nonlinear model of Figure 2 (with $\alpha= \pm 0.05$ limits) replaces the linear model of a non-reheat turbine in Figure 1. This is to take into account the generating rate constraint (GRC), i.e., the practical constraint on the response speed of a turbine. The overall system can be modeled as a multivariable system in the following form

$$
\begin{aligned}
& \dot{x}=A x+B u+\Gamma d, \\
& y=c x \\
& x=\left[\begin{array}{lllllllll}
\Delta f_{1} & \Delta P_{T 1} & \Delta P_{G 1} & \Delta P_{C 1} & \Delta P_{\text {tie }} & \Delta f_{2} & \Delta P_{T 2} & \Delta P_{G 2} & \Delta P_{C 2}
\end{array}\right]^{T} \\
& u=\left[\begin{array}{ll}
u_{1} & u_{2}
\end{array}\right]^{T}, y=\left[\begin{array}{ll}
A C E_{1} & A C E_{2}
\end{array}\right]^{T}, d=\left[\begin{array}{ll}
\Delta P_{D 1} & \Delta P_{D 2}
\end{array}\right]^{T}
\end{aligned}
$$

For the two area considered in this paper, the conventional integral controller was replaced by a PID controller with the following structure:

$$
K(s)=K_{P}+\frac{K_{I}}{s}+K_{D} s
$$

Where $K_{P}$ is proportional gain, $K_{l}$ is the integral gain, and $K_{D}$ is differential gain, respectively. The control signal for PID controller can be given in the following equation.

$$
U_{i}=-K(s) * A C E_{i}(s)
$$

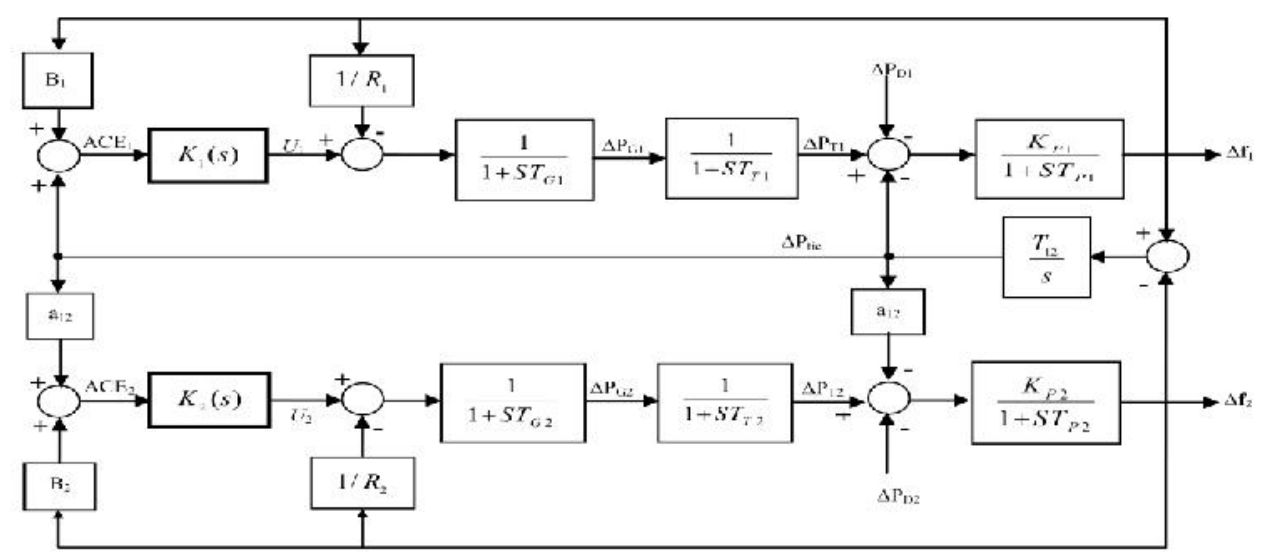

Figure 1. Two-area interconnected power system 


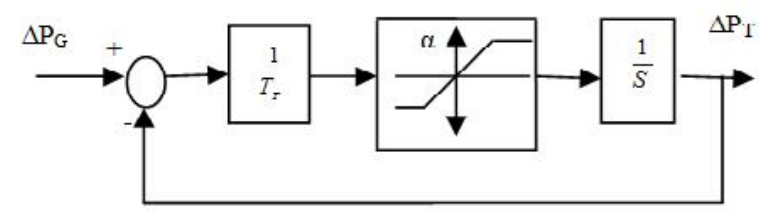

Figure 2. Nonlinear turbine model with GRC

\section{Objective Function}

The performance index which selected in this paper can be defined by the Integral of Time multiply Absolute Error (ITAE) of the frequency deviation of both areas and tie line power. Accordingly, the objective function $J$ is set to be:

$$
J=\int_{0}^{t_{s}} t\left(\left|\Delta f_{1}\right|+\left|\Delta f_{2}\right|+\left|\Delta P_{t i e}\right|\right) d t
$$

Where, $t_{s}$ is the simulation time. To simplify the study, the parameters of two interconnected areas were considered identical. The optimal parameter are such that $K 1=K 2=K$.

This study focuses on optimal tuning of controllers for nonlinear LFC and tie power control using $A B C$. The aim of the optimization is to search for the optimum PID controller parameters setting that improve the damping characteristics of the system under all operating conditions and various loads.

\section{Simulations Results}

In this section different comparative cases are examined to show the effectiveness of the proposed $A B C$ method for optimizing controller parameters. Table 1 gives the optimum values of controller parameters for different methods.

Table 1. Controller parameters for different applied cases.

\begin{tabular}{lllll}
\hline & $\begin{array}{l}\text { Conventional } \\
\text { controller }\end{array}$ & $\begin{array}{l}\text { GA PID } \\
\text { controller }\end{array}$ & $\begin{array}{l}\text { BFOA PID } \\
\text { controller }\end{array}$ & $\begin{array}{l}\text { ABC PID } \\
\text { controller }\end{array}$ \\
\hline Controller & $K_{P}=0.5865$ & $K_{P}=0.0955$ & $K_{P}=0.1317$ & $K_{P}=0.3228$ \\
parameters & $K_{I}=0.5100$ & $K_{I}=0.4712$ & $K_{I}=0.4873$ & $K_{I}=0.5633$ \\
& $K_{D}=0.1686$ & $K_{D}=0.0679$ & $K_{D}=0.2506$ & $K_{D}=0.407$ \\
\hline
\end{tabular}

The PID parameters of conventional controller, GA and BFOA due to [14]. Table 2 gives the values of the performance indices for different controllers and operating conditions. It is clear that, the values of the performance indices with the proposed controller are smaller compared to conventional controller, GA and BFOA based one. Also, the effect of saturation limit $(\alpha= \pm 0.025)$ can be seen in increasing the values of performance indices compared with $(\alpha$ $= \pm 0.05$ ) as shown in Table 2 . Moreover, conventional controller fails to stabilize the system with parameter variation test.

Table 2. Performance indices for different controllers and parameter change.

\begin{tabular}{llllll}
\hline GRC & Parameter change & ZN PID & GA PID & BFOA PID & ABC PID \\
\hline$\alpha= \pm 0.05$ & Normal & 0.6040 & 0.5513 & 0.4788 & 0.3372 \\
& $50 \% T_{12} \uparrow$ & Unstable & 0.5905 & 0.4771 & 0.3312 \\
& $50 \% T_{12} \downarrow$ & 0.6598 & 0.5921 & 0.5048 & 0.4372 \\
& $50 \% T_{G} \uparrow$ & Unstable & 0.6793 & 0.4760 & 0.3370 \\
& $50 \% T_{G} \downarrow$ & 0.6018 & 0.5563 & 0.4843 & 0.3397 \\
\hline$\alpha= \pm 0.05$ & Normal & 3.4972 & 2.4668 & 1.5078 & 1.1912 \\
& $50 \% T_{12} \uparrow$ & Unstable & 2.0784 & 1.2758 & 1.2758 \\
& $50 \% T_{12} \downarrow$ & 3.7706 & 3.1066 & 2.1568 & 1.3487 \\
& $50 \% T_{G} \uparrow$ & Unstable & 3.2398 & 1.7988 & 1.4421 \\
& $50 \% T_{G} \downarrow$ & 2.4102 & 1.8270 & 1.3011 & 1.0243 \\
\hline
\end{tabular}




\subsection{Step Increase in Demand of the First Area $\left(\Delta \boldsymbol{P}_{D_{1}}\right)$}

As the first test case, a 0.05 step increase in demand of the first area $\left(\Delta P_{D 1}\right)$ is applied at operating point 1 with saturation limit $\alpha= \pm 0.05$. The frequency deviation of the first area $\Delta f_{1}$, the frequency deviation of the second area $\Delta f_{2}$ and tie line power signal of the closed loop system are shown in Figure 3-5. It is clear from these Figures, that oscillations are greatly attenuated in the presence of the proposed controller. Moreover, the proposed method outperforms and outlasts BFOA, GA and conventional method in damping oscillations effectively and reducing settling time. Hence compared to the conventional PID controller, GA and BFOA based one; $A B C$ based controller greatly enhances the system stability and improves the damping characteristics of power system.

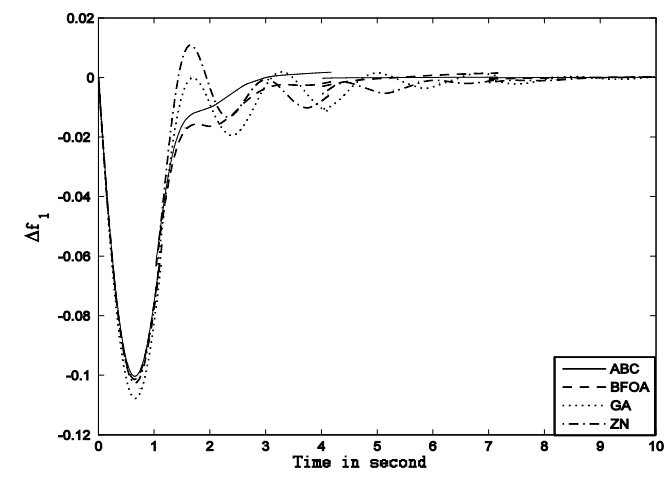

Figure 3 . Change in $f_{1}$ due to $5 \%$ disturbance in area 1

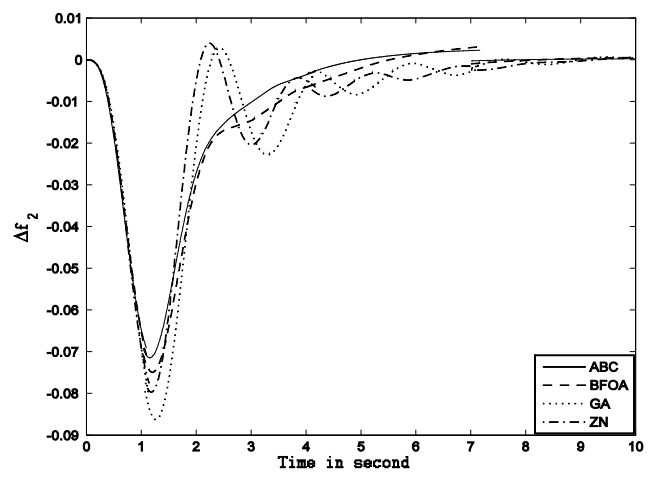

Figure 4. Change in $f_{2}$ due to $5 \%$ disturbance in area 1

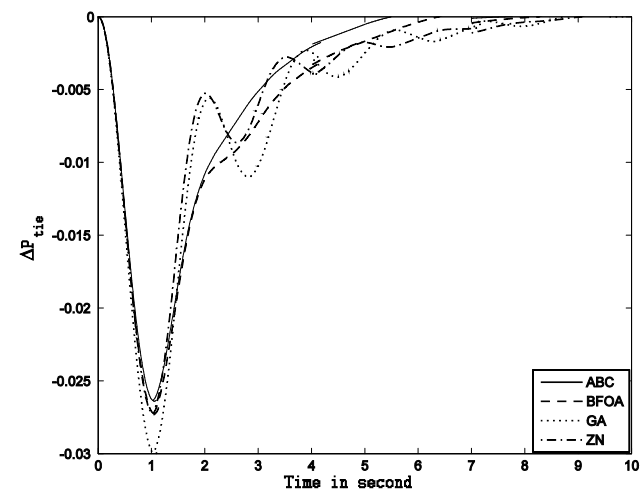

Figure 5. Change in $P_{\text {tie }}$ due to $5 \%$ disturbance in area 1

\subsection{Step Increase in Demand of the Second Area $\left(\triangle P_{D 2}\right)$}

In this case, a 0.05 step increase in demand of the second area $\left(\Delta P_{D 2}\right)$ with $\alpha= \pm 0.05$ is applied at operating point 2. The frequency deviation of the second area $\Delta f_{2}$ and tie line power of the closed loop system are shown in Figure 6 and 7. In these Figures, the conventional PID controller gives high settling time and undesirable oscillations. Also compared with BFOA and $\mathrm{GA}$, the proposed method is indeed more efficient in improving the damping characteristic of power system. 


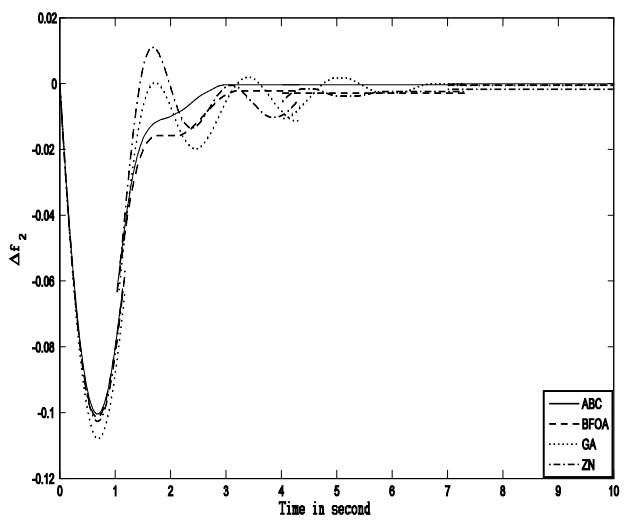

Figure 6 . Change in $f_{2}$ due to $5 \%$ disturbance in area 2

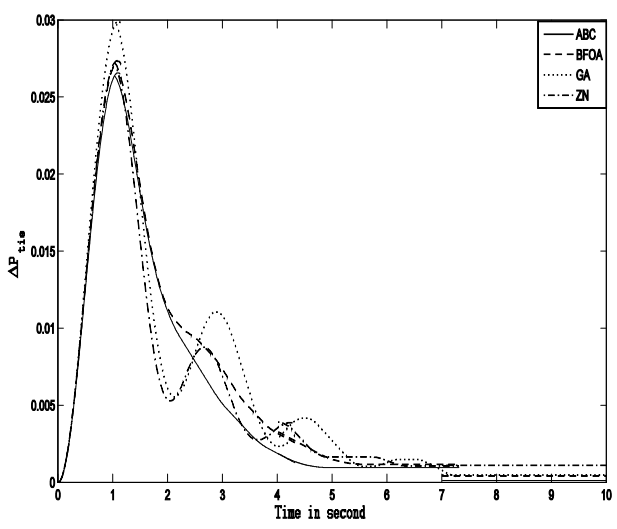

Figure 7. Change in $P_{\text {tie }}$ due to $5 \%$ disturbance in area 2

\subsection{Effect of Saturation Limit on System Response}

In this case, a 0.05 step increase in demand of the first area $\left(\Delta P_{D 1}\right)$ with $\alpha=$ \pm 0.025 is applied at operating point 3 . The responses of the closed loop system are shown in Figures 8-9. It is clear from these Figures, that the power system oscillations are poorly damped due to conventional controller. Also compared with BFOA and GA, the proposed method has a smaller settling time and system response is quickly driven back to zero.

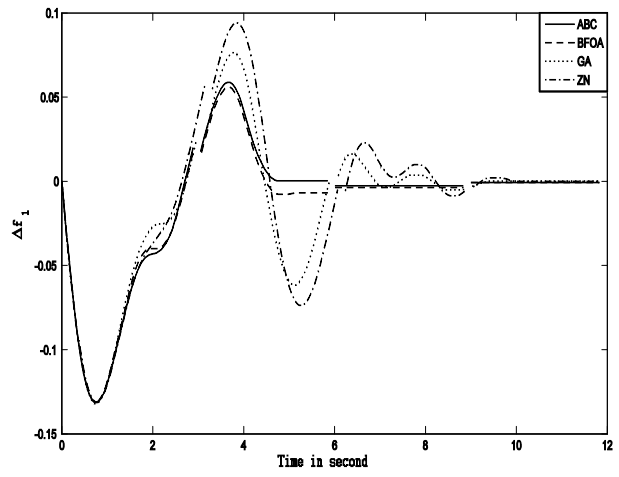

Figure 8. Change in $f_{1}$ with $\alpha= \pm 0.025$

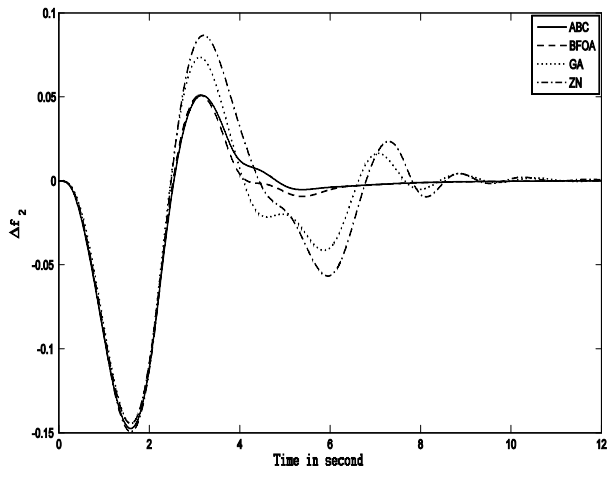

Figure 9. Change in $f_{2}$ with $\alpha= \pm 0.025$

\subsection{Effect of Parameter Variation on System Response}

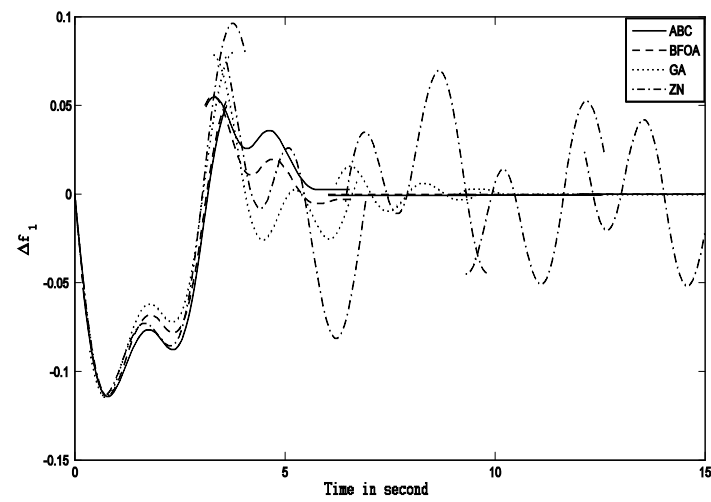

Figure 10 . Change in $f_{1}$ due to increase $T_{12}$ by $50 \%$. 
A parameter variation test with $\alpha= \pm 0.025$ is also applied to assess the robustness of the proposed controller. Figure 10 shows the response of frequency of first area with increase of $T_{12}$ by $50 \%$. the system with the proposed $A B C$ is more robust and gives better dynamic performances as compared to conventional controller, GA and BFOA.

\section{Conclusion}

$A B C$ is proposed in this paper to tune the parameters of PID controller for nonlinear LFC problem. A two area power system is considered to demonstrate the proposed method. Simulation results emphasis that the designed ABC tuning PID controller is robust in its operation and gives a superb damping performance for frequency and tie line power deviation compared to conventional PID controller, GA and BFOA tuning PID controller. Besides the simple architecture of the proposed controller it has the potentiality of implementation in real time environment.

\section{References}

[1] P Kundur. Power system stability and control. McGraw-Hill. 1994.

[2] H Saadat. Power system analysis. Tata Mcgraw-Hill. 2002.

[3] Ol Elgard. Electrical Energy System theory: an Introduction. New Delhi: McGraw-Hill. 2005.

[4] OI Elgerd, CE Fosha. Optimum megawatt-frequency control of multiarea electric energy systems. IEEE Trans. Power App. Syst. 1970; 89(4): 556-563.

[5] CE Fosha, OI Elgerd. The megawatt-frequency control problem-A new approach via optimal controltheory. IEEE Trans. Power App. Syst. 1970; 89(4): 563-577.

[6] SP Ghoshal, SK Goswami. Application of GA based optimal integral gains in fuzzy based active power-frequency control of nonreheat and reheat thermal generating systems. Elect. Power Syst. Res. 2003; 67: 79-88.

[7] SP Ghoshal. Application of GA/GA-SA based fuzzy automatic generation control of a multi-area thermal generating system. Elect. Power Syst. Res. 2004; 70: 115-127.

[8] L Pinkag, Z Hengjun, L Yuyun. Genetic algorithm optimization for AGC of multi-area power systems. Proc. of IEEE Region 10 conference on computers, communications, control and power engineering (TENCON'02). 2002: 1818-1821.

[9] $\mathrm{H}$ Golpira, H Bevrani. Application of GA optimization for automatic generation control design in an interconnected power system. Energy Conversion and Management. 2011; 52: 2247-2255.

[10] YL Abdel-Magid, MA Abido. AGC tuning of interconnected reheat thermal systems with particle swarm optimization. Proc. of the 2003 10th IEEE international conference on electronics, circuits and systems. 2003; 1: 376-379.

[11] H Gozde, MC Taplamacioglu, I Kocaarslan, MA Senol. Particle swarm optimization based PI-controller design to load-frequency control of a two area reheat thermal power system. J Therm Sci Technol. 2010; 30(1): 13-21.

[12] H Shabani, B Vahidi, M Ebrahimpour. A robust PID controller based on imperialist competitive algorithm for load-frequency control of power systems. ISA Trans. 2013; 52(1): 88-95.

[13] ES Ali, SM Abd-Elazim. Bacteria foraging optimization algorithm based load frequency controller for interconnected power system. Int. J Electr. Power Energy Syst. 2011;33(3): 633-638.

[14] ES Ali, SM Abd-Elazim. BFOA based design of PID controller for two area Load Frequency Control with nonlinearities. Electrical Power and Energy Systems. 2013; 51: 224-231.

[15] M Elsisi, M Soliman, MAS Aboelela, W Mansour. Dual Proportional Integral Controller of Two-Area Load Frequency Control Based Gravitational Search Algorithm. TELKOMNIKA Indonesian Journal of Electrical Engineering. 2015; 15(1): 26-35.

[16] D Karaboga. An idea based on honey bee swarm for numerical optimization. Technical report-TR06, Erciyes University Engineering Faculty Computer Engineering Department. 2005.

[17] D Karaboga, B. Basturk. A powerful and efficient algorithm for numeric optimization: artificial bee colony (ABC) algorithm. J Global Optim. 2007; 39(3): 459-471.

[18] D Karaboga, B Akay. A comparative study of Artificial Bee Colony algorithm. Applied Mathematics and Computation. 2009; 214(1): 108-132. 